\title{
Prevalence of human papillomavirus DNA in various histological subtypes of cervical adenocarcinoma: a population-based study
}

\author{
Hee J An ${ }^{1}$, Kyu R Kim ${ }^{2}$, In S Kim ${ }^{3}$, Dong W Kim ${ }^{4}$, Moon H Park ${ }^{5}$, In A Park ${ }^{6}$, Kwang S Suh ${ }^{7}$, \\ Eun J Seo ${ }^{8}$, Sun H Sung ${ }^{9}$, Jin H Sohn ${ }^{10}$, Hye K Yoon ${ }^{11}$, Eun D Chang ${ }^{8}$, Hyun I Cho ${ }^{12}$, \\ Ji Y Han ${ }^{13}$, Sung R Hong ${ }^{10}$ and Geung H Ahn ${ }^{10}$
}

${ }^{1}$ Department of Pathology, Pochon CHA University, Sungnam, South Korea; ${ }^{2}$ Department of Pathology, Ulsan University, Seoul, South Korea; ${ }^{3}$ Department of Pathology, Korea University, Seoul, South Korea; ${ }^{4}$ Department of Pathology, Soonchunhyang University, Seoul, South Korea; ${ }^{5}$ Department of Pathology, Hanyang University, Seoul, South Korea; ${ }^{6}$ Department of Pathology, Seoul University, Seoul, South Korea; ${ }^{7}$ Department of Pathology, Chungnam University, Daejon, South Korea; ${ }^{8}$ Department of Pathology, Catholic University, Seoul, South Korea; ${ }^{9}$ Department of Pathology, Ewha University, Seoul, South Korea; ${ }^{10}$ Department of Pathology, Sungkyunkwan University, Seoul, South Korea; ${ }^{11}$ Department of Pathology, Inje University, Busan, South Korea; ${ }^{12}$ Department of Pathology, Gachon University, Inchon, South Korea and ${ }^{13}$ Department of Pathology, Inha University, Inchon, South Korea

\begin{abstract}
The role of human papilloma virus (HPV) infection in the development of cervical carcinoma is well established, however, the prevalence of HPV DNA in cervical adenocarcinoma varies from study to study. It appears to be caused by a number of factors, one of which is that cervical adenocarcinomas comprise a heterogeneous group of multiple subtypes. To clarify the impact of HPV infection on the development of cervical adenocarcinoma with diverse histological subtypes, we performed a population-based study in Korean women from 15 different institutes for the status of HPV infection in adenocarcinoma of uterine cervix. A total of 432 cervical adenocarcinomas from 1997 to 2001 were reviewed and classified according to the modified WHO classification. For 135 cases, HPV typing was performed with HPV DNA chip (82 cases) and PCR HPV typing (53 cases), using formalin-fixed, paraffin-embedded archival tissue. The overall prevalence of HPV infection in cervical adenocarcinoma was $90 \%$. The infection of HPV 16 and/or HPV 18 accounted for $78 \%$ of HPV-positive adenocarcinomas. Multiple HPV types were found in $13 \%$ of the cases. The HPV DNA was rarely detected in minimal deviation adenocarcinoma. Interestingly, HPV 16 was a predominant type in endometrioid and villoglandular types, whereas HPV 16 and HPV 18 were detected with equal prevalence in other subtypes. In conclusion, HPV infection, mostly HPV 16 and HPV 18, is highly associated with most of the cervical adenocarcinomas, whereas endometrioid and villoglandular type have a different pattern of HPV infection status. Minimal deviation adenocarcinoma does not seem to be related with HPV infection.
\end{abstract}

Modern Pathology (2005) 18, 528-534, advance online publication, 22 October 2004; doi:10.1038/modpathol.3800316

Keywords: cervical adenocarcinoma; HPV infection; HPV DNA Chip; PCR-based HPV typing

The incidence and proportion of adenocarcinoma relative to squamous cell carcinoma in the uterine cervix has been increasing over the past several

Correspondence: Dr GH Ahn, MD, Department of Pathology, Samsung Medical Center, Sungkyunkwan University College of Medicine, 50, Ilwon-Dong, Kangnam-Gu, Seoul 143-230, South Korea.

E-mail: gahn@smc.samsung.co.kr

The above-mentioned authors belong to The Gynecological Pathology Study Group of the Korean Society of Pathologists

Received 26 July 2004; revised and accepted 9 September 2004; published online 22 October 2004 decades. Recent reports indicated that the adenocarcinoma accounted for $20-25 \%$ in uterine cervical cancer compared with only $5-15 \%$ in the past. ${ }^{1-3}$ The epidemiologic risk for cervical adenocarcinoma is similar to those for invasive squamous cell carcinoma, such as multiple sexual partners and the early onset of sexual intercourse, which are related to the risk factors of human papilloma virus (HPV) infection. ${ }^{4}$ Whereas the role of HPV infection in the development of cervical squamous cell carcinoma is well established, the pathogenetic role of the HPV in the cervical adenocarcinoma is still 
unclear. The previously reported prevalence of HPV infection in cervical adenocarcinoma varies significantly from study to study. ${ }^{5-7}$ It has been generally believed that the HPV 18 is more frequently associated with cervical adenocarcinoma in contrast to HPV 16 in cervical squamous cell carcinoma. ${ }^{8-10}$

The causal relationship between HPV infection and cervical adenocarcinoma is further complicated by the fact that cervical adenocarcinoma encompasses several heterogeneous histological subtypes. The majority of cervical adenocarcinoma is mucinous adenocarcinoma including endocervical, intestinal, and signet ring cell type. The minor component of cervical adenocarcinoma includes a variety of histological subtypes, such as endometrioid, minimal deviation, villoglandular, clear cell, serous and mesonephric adenocarcinoma, and a mixture of those subtypes.

To investigate the impact of HPV infection on the development of diverse histological types of cervical adenocarcinoma in Korean women, we examined the HPV genotypes according to the various subtypes of cervical adenocarcinomas, which were diagnosed during January, 1997 to December, 2001 from the 15 different institutes in Korea.

\section{Material and methods}

\section{Case Selection and Histological Subtyping}

All the cases were retrieved from 15 institutes in Korea, which were diagnosed from 1997 to 2001 obtained by LEEP conization or hysterectomy. A total of 432 cases of primary invasive adenocarcinoma were enrolled for the study and the histological slides of each case were reviewed by three other gynecological pathologists to classify the histological subtype according to the standard histological criteria. ${ }^{11,12}$ The presence of associated cervical intraepithelial neoplasia lesion was recorded. Clinicopathological characteristics were obtained from the patient's clinical records.

\section{HPV Typing}

For 53 cases from two Institutes, HPV testing has been performed at the time of the diagnosis using PCR-based HPV typing. Among the cases which were not done HPV testing previously, 82 cases were available for HPV genotyping and were conducted HPV typing using HPV DNA microarray method. Detailed protocols for HPV typing are as follows (the assay methods for HPV typing are not approved yet by the US FDA):

PCR (polymerase-chain-reaction)-based HPV typing with enzyme restriction

The DNA was isolated from the $5 \mu \mathrm{m}$ sections of formalin-fixed, paraffin-embedded tissue. The samples were deparaffinized in microcentrifuge tubes, then digested by $400 \mu \mathrm{g} / \mathrm{ml}$ proteinase-K in $200 \mu \mathrm{l}$ TE10E1 buffer at $55^{\circ} \mathrm{C}$ for $24-48 \mathrm{~h}$. After heat inactivation of the enzyme, the DNA was isolated using phenol/chloroform/isoamyl alcohol with ethanol down.

Amplification for HPV typing was performed as described by Fujinaga. ${ }^{13} \mathrm{~A}$ pair of oligonucleotide primers (Takara Bio Inc. Japan) specific for consensus sequences within the E6, E7 open reading frames of HPV-16, -18, -31, and -33. The sequence of the sense primer was $5^{\prime}$-TGTCAAAAACCGTTGT GTCC-3', and that of the antisense primer was $5^{\prime}$-GAGCTGTCGCTTAATTGCTC- ${ }^{\prime}$. As a control, $\beta$ globin was amplified with sense primer : $5^{\prime}$-CAACT TCATCCACGTTCACC- ${ }^{\prime}$, and antisense primer : $5^{\prime}$-GAAGAGCCAAGGACAGGTAC $-3^{\prime}$. In each reaction, a negative control was included in which the template DNA was omitted. The PCR products were extracted once with an equal volume of phenol: chloroform:isoamylalcohol (25:24:1,v/v). Following ethanol precipitation, the DNA was resuspended in distilled water. Typing of the PCR products was performed by restriction enzyme digestion. The product was digested with 3-4 U of AvaII or AfaI in $10 \mu \mathrm{l}$ reaction mixture for $2 \mathrm{~h}$ at $37^{\circ} \mathrm{C}$. Then $10 \mu \mathrm{l}$ of the reaction products were analysed by electrophoresis on $3 \%$ agarose gels (Figure 1). The consensus primer pairs produced 238, 268, 232 and $244 \mathrm{bp}$ PCR products with HPV-16, -18, -31, and -33, respectively. AvaII digestion of 238,268 , and $244 \mathrm{bp}$ products yielded 157/81, 172/96, and 136/ 108 bp fragments with HPV-16, -18, and -33, respectively. HPV-31 was identified by AfaI digestion with $117 / 115 \mathrm{bp}$ fragments.

\section{$H P V$ genotyping using HPV DNA microarray method}

For the HPV genotyping of 82 cases, we used a commercially available HPVDNAChip ${ }^{\circledR}$ (Biomedlab Co., Seoul, Korea), a PCR-based DNA microarray

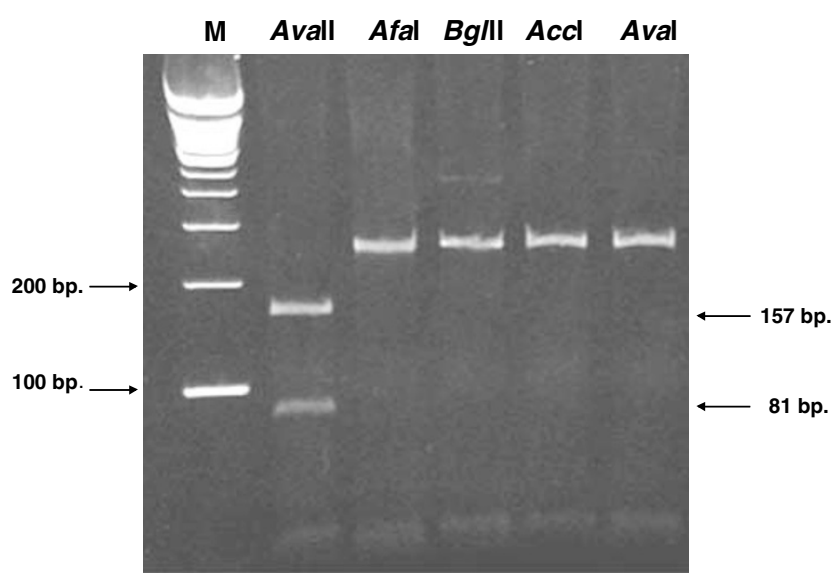

Figure 1 Detection of HPV 16 by PCR HPV typing with enzyme restriction. Gel electrophoresis after digestion of amplified DNA by various restriction enzymes. AvaII yields $157 / 81 \mathrm{bp}$ length fragments for HPV 16 in lane 1. M: marker. 
system and followed the manufacturer's protocol for the assay. HPVDNAChip ${ }^{\circledR}$ contains 22 type specific probes; 15 of the high-risk group (16/18/31/33/35/ $39 / 45 / 51 / 52 / 56 / 58 / 59 / 66 / 68 / 69)$ and seven of the low-risk group (6/11/34/40/42/43/44). In all, 22 type-specific 30 -mer oligonucleotide probes containing an amine group at the $5^{\prime}$ terminus were immobilized onto a chip slide glass. A slide has four chambers and each chamber has two compartments containing all probes dotted in duplicate; thus each test is carried out in duplicate for each sample. DNA was isolated from the $5 \mu \mathrm{m}$ section of paraffinembedded tissue using a DNA isolation kit (Intron Biotech.Inc., Seoul, Korea) and target L1 regions of HPV DNA were amplified and labeled by a single dye, Cy5-dUTP, (NEN ${ }^{\circledR}$ Life Science Products, Inc., Boston, MA, USA) using consensus GPd5 + / GP6d + primer (GP5d + , 5'-tttkttachgtkgtdgatacyac3'; GP6d +, 5'-gaaahataaaytgyaadtcataytc-3'; k,g/t; h, t/a/c; d, a/t/g; y, t/c). $\beta$-Globin was amplified using PCR with PC03/PC04 primers (PC03, 5'-acacaa ctgtgttcactagc- $3^{\prime}$; PC04, 5'-caacttcatccacgttcacc-3') as internal controls. The PCR products of all samples were detected by electrophoresis through a $2 \%$ agarose gel, and the product size of HPV DNA was $150 \mathrm{bp}$. A mixture of $20 \mu \mathrm{l}$ of the HPV-amplified product and $10 \mu \mathrm{l}$ of the $\beta$-globin amplified product was denatured by adding $3 \mathrm{~N} \mathrm{NaOH}$ solution $(10 \%$ $\mathrm{v} / \mathrm{v}$ ), incubating for $5 \mathrm{~min}$ at room temperature, then neutralized by adding $1 \mathrm{M}$ Tris-HCl $(\mathrm{pH} 7.2,5 \%$ $\mathrm{v} / \mathrm{v})$. This was followed with $3 \mathrm{~N} \mathrm{HCl}(10 \% \mathrm{v} / \mathrm{v})$ and cooling on ice for $5 \mathrm{~min}$. The samples were mixed with a hybridization solution made up of $6 \times$ SSPE (saline-sodium phosphate-EDTA buffer, Sigma, St Louis, MO, USA) and $0.2 \%$ SDS, and then applied onto the DNA chip. Hybridization was performed at $40^{\circ} \mathrm{C}$ for $2 \mathrm{~h}$ and was followed by washing with $3 \times$ SSPE for $2 \mathrm{~min}, 1 \times$ SSPE for $2 \mathrm{~min}$, and air-drying at room temperature. Hybridized HPV DNA was visualized using a DNA Chip Scanner (GSI Lumonics ${ }^{\circledR}$, Scanarray lite, Ottawa, Canada). HPV amplicons can be hybridized with corresponding type-specific oligonucleotide probe, and visualized on HPV DNA Chip slide as double-positive spots when HPV DNA is present in the samples. DNA from HPV 16-positive SiHa cell line was used as a positive control in each PCR reaction. None of the negative controls revealed HPV positivity. The image of HPV DNA chip with various HPV types is shown in Figure 2.

\section{Statistical analysis}

The statistical analysis was performed using SAS version 8.0. The test for several population proportions using $\chi^{2}$-test was used to compare the predominant HPV genotypes among the various histological subtypes, and to evaluate the differences of the proportions of clinical stages between the histological subtypes. The differences between the mean ages of various subtypes were analyzed with the Student's $t$-test. $P$-values $<0.05$ were considered statistically significant.

\section{Results}

\section{Clinicopathological Characteristics of Cervical Adenocarcinoma in Korean Women}

The clinicopathological characteristics were summarized in Table 1. The endocervical type occupied the major subtype (272 cases; $63 \%$ ) of the adenocarcinoma, which was followed by adenosquamous carcinoma (44 cases; $10 \%$ ), intestinal (28 cases; $7 \%$ ), and endometrioid type (24 cases; $6 \%$ ). The remaining other subtypes comprised two clear cell adenocarcinoms, one serous adenocarcinoma, one glassy cell carcinoma, one adenoid cystic carcinoma. The mean age was 47.5 years. Among the various a

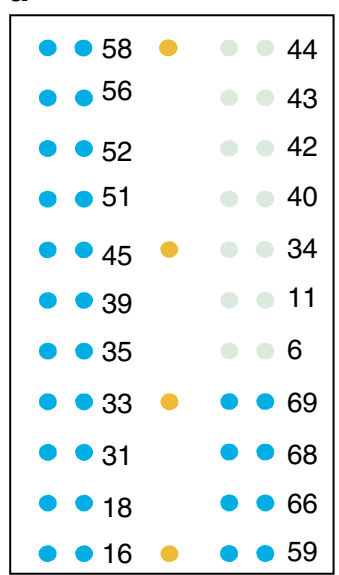

b

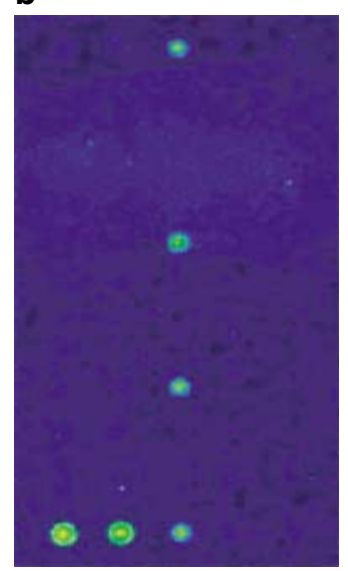

c

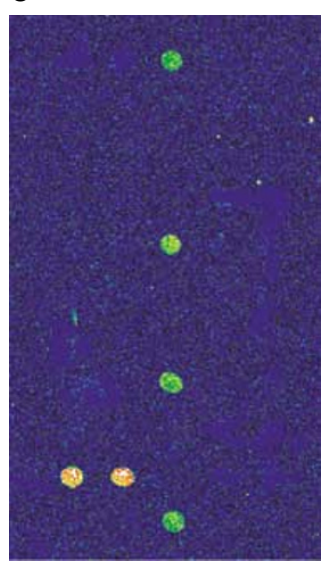

d

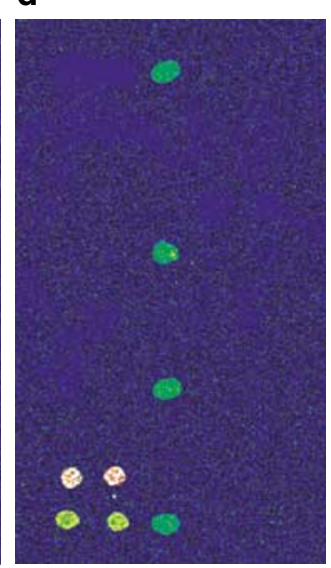

e

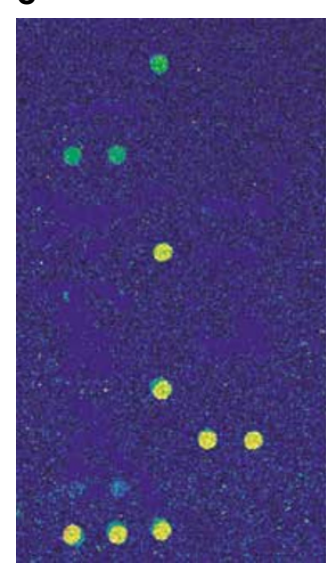

Figure 2 Detection of HPV genotypes by HPV DNA Chip. (a) The format of DNA chip containing 22 HPV types. Each chip harbors a pair of the oligonucleotide probes of the $22 \mathrm{HPV}$ genotypes. Orange dots represent $\beta$-globin, blue dots are probes of 15 high-risk HPV types, and green dots are probes of 7 low-risk HPV types. (b) HPV 16 positive case. (c) HPV 18 positive case. (d) The multiple infection with HPV 16 and 18. (e): The multiple infection with HPV 16, 68, and 52. 
Table 1 Clinicopathological characteristics of various histological subtypes of cervical adenocarcinomas in Korean women

\begin{tabular}{|c|c|c|c|c|c|c|c|}
\hline & No. $(\%)$ & Mean age & CIN III & Stage $1(\%)$ & Stage $2(\%)$ & Stage $3(\%)$ & Stage $4(\%)$ \\
\hline \multicolumn{8}{|l|}{ Mucinous } \\
\hline Endocervical & $272(63 \%)$ & $47.2+9.7$ & $25(7 \%)$ & 80 & 4 & 13 & 1 \\
\hline Intestinal & $28(7 \%)$ & $43.9 \pm 8.2$ & 0 & 68 & 7 & 25 & 0 \\
\hline Signet ring cell & $12(3 \%)$ & $44.1 \pm 7.9$ & 0 & 83 & 0 & 17 & 0 \\
\hline Endometrioid & $24(6 \%)$ & $46.9 \pm 7.8$ & $1(4 \%)$ & 83 & 4 & 13 & 0 \\
\hline Minimal deviation AC & $5(1 \%)$ & $51.5 \pm 4.7$ & 0 & 80 & 0 & 20 & 0 \\
\hline Villoglandular AC & $8(2 \%)$ & $46.3+8.8$ & 0 & 100 & 0 & 0 & 0 \\
\hline Adenosquamous Ca. & $44(10 \%)$ & $50.3 \pm 10.3$ & $44(100 \%)$ & 73 & 5 & 23 & 0 \\
\hline Mixed & $34(7 \%)$ & $55.3 \pm 13.6$ & $2^{\mathrm{a}}(6 \%)$ & 82 & 9 & 9 & 0 \\
\hline Other $^{b}$ & $5(1 \%)$ & $51.7 \pm 18.3$ & 0 & 83 & 0 & 17 & 0 \\
\hline Total & $432(100 \%)$ & $47.5 \pm 9.6$ & $71(16 \%)$ & 80 & 4 & 15 & 1 \\
\hline
\end{tabular}

AC: adenocarcinoma.

${ }^{\mathrm{a}}$ Include endocervical+signet ring, endocervical+small cell.

b Other types include two clear cell ACs, one serous AC, one glassy cell carcinoma, one adenoid cystic carcinoma.

Table 2 Prevalence of HPV genotypes according to various histological subtypes of cervical adenocarcinoma (\%)

\begin{tabular}{|c|c|c|c|c|c|c|c|c|c|c|c|}
\hline Subtype & $\mathrm{n}$ & $H P V(-)$ & $H P V(+)$ & $H P V 16^{\mathrm{a}}$ & $H P V 18^{\mathrm{a}}$ & $H P V 16+18^{\mathrm{a}}$ & $H P V 33$ & $H P V 45$ & $H P V 59$ & $H P V 68$ & HPV other \\
\hline Endocervical $^{\mathrm{b}}$ & 65 & $\begin{array}{c}3 \\
(5)\end{array}$ & $\begin{array}{c}62 \\
(95)\end{array}$ & $\begin{array}{c}22 \\
(36)\end{array}$ & $\begin{array}{c}21 \\
(34)\end{array}$ & $\begin{array}{c}4 \\
(6)\end{array}$ & $\begin{array}{c}4 \\
(6)\end{array}$ & 0 & 0 & 0 & $\begin{array}{c}11 \\
(18)\end{array}$ \\
\hline Intestinal $^{\mathrm{b}}$ & 21 & $\begin{array}{c}3 \\
(14)\end{array}$ & $\begin{array}{c}18 \\
(86)\end{array}$ & $\begin{array}{c}5 \\
(28)\end{array}$ & $\begin{array}{c}5 \\
(28)\end{array}$ & $\begin{array}{c}1 \\
(5)\end{array}$ & $\begin{array}{c}1 \\
(5)\end{array}$ & $\begin{array}{c}1 \\
(5)\end{array}$ & 0 & 0 & $\begin{array}{c}5 \\
(28)\end{array}$ \\
\hline Signet ring cell ${ }^{\mathrm{b}}$ & 8 & $\begin{array}{c}2 \\
(25)\end{array}$ & $\begin{array}{c}6 \\
(75)\end{array}$ & $\begin{array}{c}1 \\
(17)\end{array}$ & $\begin{array}{c}1 \\
(17)\end{array}$ & $\begin{array}{c}2 \\
(33)\end{array}$ & $\begin{array}{c}1 \\
(17)\end{array}$ & 0 & $\begin{array}{c}1 \\
(17)\end{array}$ & 0 & 0 \\
\hline Endometrioid & 10 & $\begin{array}{c}2 \\
(20)\end{array}$ & $\begin{array}{c}8 \\
(80)\end{array}$ & $\begin{array}{c}8 \\
(100)\end{array}$ & 0 & 0 & 0 & 0 & 0 & 0 & 0 \\
\hline Minimal deviation & 4 & $\begin{array}{c}3 \\
(75)\end{array}$ & $\begin{array}{c}1 \\
(25)\end{array}$ & $\begin{array}{c}1 \\
(100)\end{array}$ & 0 & 0 & 0 & 0 & 0 & 0 & 0 \\
\hline Villoglandular & 5 & 0 & $\begin{array}{c}5 \\
(100)\end{array}$ & $\begin{array}{c}4 \\
(80)\end{array}$ & 0 & $\begin{array}{c}1 \\
(20)\end{array}$ & 0 & 0 & 0 & 0 & 0 \\
\hline Adenosquamous & 21 & $\begin{array}{c}1 \\
(5)\end{array}$ & $\begin{array}{c}20 \\
(95)\end{array}$ & $\begin{array}{c}9 \\
(45)\end{array}$ & $\begin{array}{c}8 \\
(40)\end{array}$ & $\begin{array}{c}1 \\
(5)\end{array}$ & 0 & 0 & 0 & $\begin{array}{c}1 \\
(5)\end{array}$ & $\begin{array}{c}1 \\
(5)\end{array}$ \\
\hline Glassy cell & 1 & 0 & $\begin{array}{c}1 \\
(100)\end{array}$ & $\begin{array}{c}1 \\
(100)\end{array}$ & 0 & 0 & 0 & 0 & 0 & 0 & 0 \\
\hline Total & 135 & $\begin{array}{c}14 \\
(10)\end{array}$ & $\begin{array}{l}121 \\
(90)\end{array}$ & $\begin{array}{c}51 \\
(42)\end{array}$ & $\begin{array}{c}35 \\
(29)\end{array}$ & $\begin{array}{c}9 \\
(7)\end{array}$ & $\begin{array}{c}6 \\
(5)\end{array}$ & $\begin{array}{c}1 \\
(1)\end{array}$ & $\begin{array}{c}1 \\
(1)\end{array}$ & $\begin{array}{c}1 \\
(1)\end{array}$ & $\begin{array}{c}17 \\
(14)\end{array}$ \\
\hline
\end{tabular}

\footnotetext{
${ }^{a}$ Include the multiple infection; HPV 16 including five cases of multiple infection (four HPV 16+68, one HPV 16+56); HPV 18 including four cases of multiple infection (two HPV 18+33, one HPV 18+58, one HPV 18+45+52); HPV 16+18 including two cases of multiple infection (one HPV 16+18+56, one HPV 16+18+11).

${ }^{\mathrm{b}}$ Include the mixed type with each subtype.

HPV other means HPV types other than HPV 16, 18, 33, 45, 58, 59, 68.
}

histological types, the mean age of intestinal type was the youngest (43.9 years), whereas that of minimal deviation adenocarcinoma was the oldest (51.5 years). However, these differences were not statistically significant. Cervical intraepithelial neoplasia III was accompanied with adenocarcinoma in 71 of 432 cases $(16 \%)$, predominantly with endocervical type (25/272 cases; $7 \%)$, when excluding the adenosquamous carcinoma.

Most of the cases of adenocarcinoma were stage I $(80 \%)$ at the time of the diagnosis. In respect to the association between the tumor stage and the specific histological subtype, there was a tendency that the cases of the intestinal type (stage I vs stage II vs stage
III; 68 vs 7 vs 25\%) were in the higher tumor stage than the other types. However, this tendency was not statistically significant ( $\chi^{2}$-test, $P=0.25$ ).

\section{HPV Prevalence According to the Various Histological Subtypes}

The overall prevalence of HPV infection (Table 2) associated with invasive cervical adenocarcinoma was $90 \%$ (121/135 cases). However, the minimal deviation adenocarcinoma was rarely associated with HPV infection, as shown in the finding that the HPV DNA was detected in only one case $(25 \%)$. 


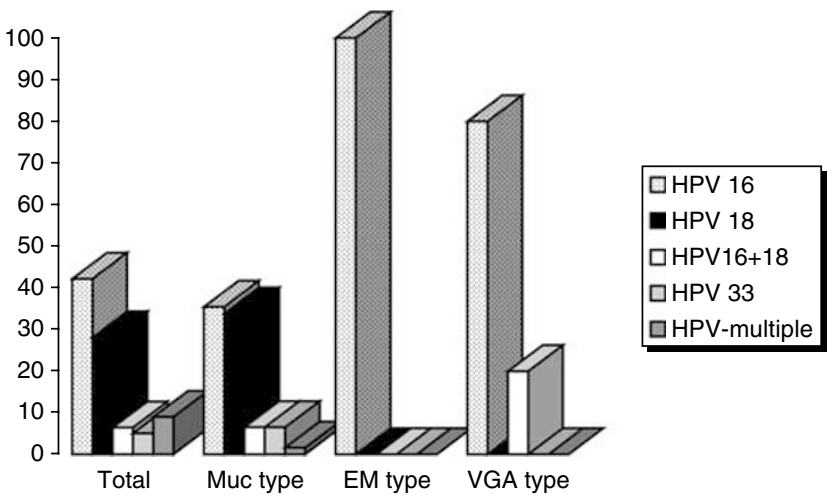

Figure 3 Comparison of the frequency of HPV genotypes according to the various histological subtypes. HPV 16 and 18 were detected with almost equal prevalence in the mucinous type, whereas HPV 16 was more predominant in endometrioid $\left(\chi^{2}\right.$-test, $P<0.01)$ and villoglandular types $\left(\chi^{2}\right.$-test, $\left.P<0.05\right)$. Muc: mucinous type; EM: Endometrioid type; VGA: villoglandular adenocarcinoma.

The most prevalent viral type was HPV 16 (42\%), which was followed by HPV 18(29\%), HPV $16+$ 18(7\%), and HPV 33 (5\%).

With regard to the HPV genotypes according to the histological subtypes, the endometrioid and villoglandular subtypes were more strongly associated with the HPV 16 infection than the other types $\left(\chi^{2}\right.$ test, $P<0.05)$. All the cases of endometrioid type and the villoglandular type were positive for HPV 16 (Figure 3), whereas the cases of the mucinous type including endocervical, intestinal and signet ring cell types showed the equal prevalence for HPV 16 and HPV 18.

Multiple HPV infection was detected in 13\% (18/ 135 cases) including seven cases of HPV $16+18$ Either HPV 16 or 18 was always included in all cases of multiple infection. HPV 68 (4/18 cases) was the next most common type in the multiple infection other than HPV 16 and/or HPV 18. The other HPV types detected in multiple infection included HPV $11,33,52,56$, and 58. Multiple HPV infection was not associated with a particular histological subtype or a coexistence of cervical intraepithelial neoplasia III.

There was no association between the tumor stage and the presence of HPV DNA or multiple HPV infection or a particular HPV genotype.

\section{Discussion}

It is now well established that oncogenic HPVs are causal factors in the development of cervical carcinoma and its precursor lesions. The overall frequency of HPV DNA associated with cervical squamous cell carcinoma has been reported to be 91-100\%. ${ }^{14-16}$ Among the well-known oncogenic HPV types, HPV 16 has been found to be the most predominant type in the patients with cervical squamous cell carcinoma and its precursor le- sions. $^{8,9,14,16}$ The recent studies for the HPV prevalence in cervical carcinoma in Korean women ${ }^{17,18}$ have revealed that HPV 16 was the most predominant type in accordance with the results of the other studies from Western countries. Meanwhile, HPV 58 and HPV 18 were the second most common HPV group in Korean patients with cervical carcinomas and high-grade squamous intraepithelial lesions, whereas HPV 18, HPV45 and HPV 31 were the next in other countries. ${ }^{8}$

As to the role of HPV on the cervical adenocarcinoma, HPV 18 was reported to be a preferential type in cervical adenocarcinoma in contrast to HPV 16 in cervical squamous cell carcinoma. ${ }^{5,6,19}$ Nonetheless, the causal linkage of HPV infection to the cervical adenocarcinoma has not been considered as strong as it is for the squamous cell carcinoma of the cervix. ${ }^{5,6}$ However, the recent more sensitive techniques have made it possible to identify the higher rate of HPV infection in adenocarcinoma with a frequency of $85 \%$ or more. ${ }^{19-21}$ In this study, we used a recently developed HPV DNA Chip for the detection of HPV DNA in 82 of 135 cases. This method is based on the polymerase chain reaction with an advantage to detect single and multiple infection of 22 HPV genotypes at once and has reported to be a very sensitive method comparable with Hybrid Capture II assay. ${ }^{17,22}$

In the present study, we found that the overall HPV prevalence in the cervical adenocarcinoma among Korean women was 90\%, and HPV 16 (42\%) appeared to be more prevalent than HPV $18(29 \%)$, which was followed by HPV $16+18(7 \%)$ and HPV $33(5 \%)$. It is of interest that the particular subtypes such as endometrioid and villoglandular type were predominantly associated with HPV 16 . This fact might be responsible for the highest prevalence of HPV 16 in this study, because the cases of these types examined for the HPV DNA analysis accounted for the higher proportion $(11 \%)$ of the total cases examined than the natural prevalence $(7 \%)$. In the major subtypes including the mucinous type, HPV 18 (32\%) and HPV 16 (33\%) were detected in almost equal frequency. This result was in accordance with the recent reports by other investigators of Western countries that showed the similar prevalence rate between HPV 16 and HPV 18 in cervical adenocarcinoma. ${ }^{6,20,23}$ Accordingly, it is very clear that HPV 18 has a stronger association with cervical adenocarcinoma than with cervical squamous cell carcinoma, where the frequency of HPV 18 (11.4-13.7\%) was much less common than that of the cervical adenocarcinoma. Bearing in mind that HPV 18-related cervical carcinomas were associated with poor prognostic factors or poor survival, ${ }^{24,25}$ the high frequency of HPV 18 in cervical adenocarcinoma may be implicated in the poorer 5-year survivals of cervical adenocarcinoma compared to squamous cell carcinoma with the same stages as reported by several investigators. ${ }^{3,26,27}$ 
As for the minimal deviation adenocarcinoma (MDA), HPV DNA was rarely detected except one case in this study. This result is consistent with the previous reports to date ${ }^{28-30}$ in which only one case among a total of 10 cases was positive for HPV DNA. The recent molecular study for nine cases of MDA reported the loss of heterozygosity on the chromosome 19p13.3. ${ }^{31}$ Taken together, MDA seems to have a distinct pathogenetic background different from the other types of cervical adenocarcinoma.

Multiple HPV infection was identified in 13\% in our study, which is similar to that in squamous cell carcinoma $(13.7 \%)$ reported in a large series for Korean women. ${ }^{17}$ The influence of multiple HPV infection on the development of cervical carcinoma is still controversial. However, considering the higher frequency of multiple infection in normal controls $(24.2 \%)^{17}$ than that in adenocarcinoma $(13 \%)$, it does not appear to give an additive influence to the carcinogenesis of adenocarcinoma.

To our knowledge, this population-based study is the largest series among the studies that have been reported to date as for the relationship between 22 HPV genotypes and the various histological subtypes of cervical adenocarcinoma. We found that the mucinous-type adenocarcinoma was highly associated with HPV 16 and HPV 18, whereas the endometrioid and villoglandular type were predominantly related to HPV 16. Minimal deviation adenocarcinoma was a distinct subtype, which was not associated with HPV infection. In addition, multiple HPV infection did not seem to be associated with the development of cervical adenocarcinoma.

\section{References}

1 Hepler TK, Kockerty MT, Randal LM. Primary adenocarcinoma of the cervix. Am J Obstet Gynecol 1952; 63:800-808.

2 Davis JR, Moon LB. Increased incidence of adenocarcinoma of the uterine cervix. Obstet Gynecol 1975;45: 79-83.

3 Smith HO, Tiffany MF, Qualls CR, et al. The rising incidence of adenocarcinma relative to squamous cell carcinoma of the uterine cervix in the United States-a 24 year population-based study. Gyn Oncol 2000;78: 97-105.

4 Ursin G, Pike MC, Preston-Martin S, et al. Sexual, reproductive, and other risk factors for adenocarcinoma of the cervix: results from a population-based casecontrol study. Cancer Cause Control 1996;7:391-401.

5 Duggan MA, McGregor SE, Benoit JL, et al. The human papillomavirus status of invasive cervical adenocarcinoma: a clinicopathological and outcome analysis. Hum Pathol 1995;26:319-325.

6 Tenti P, Romagnoli S, Silini E, et al. Human papillomavirus types 16 and 18 infection in infiltrating adenocarcinoma of the cervix: PCR analysis of 138 cases and correlation with histologic type and grade. Am J Clin Pathol 1996;106:52-56.
7 Skyldberg BM, Murray E, Lambkin H, et al. Adenocarcinoma of the uterine cervix in Ireland and Sweden: human papillomavirus infection and biologic alterations. Mod Pathol 1999;12:675-682.

8 Bosch FX, Manos MM, Munoz N, et al. Prevalence of human papillomavirus in cervical cancer: a worldwide perspective. International Biological Study on Cervical Cancer (IBSCC) Study Group. J Natl Cancer Inst 1995; 87:796-802.

9 Iwasawa A, Nieminen P, Lehtinen M, et al. Human papillomavirus DNA in uterine cervix squamous cell carcinoma and adenocarcinoma detected by polymerase chain reaction. Cancer 1996;77:2275-2279.

10 Lizano M, Berumen J, Guido MC, et al. Association between human papillomavirus type 18 variants and histopathology of cervical cancer. J Natl Cancer Inst 1997;89:1227-1231.

11 Wright TC, Ferenczy A, Kurman RJ. Carcinoma and other tumors of the cervix. In: Kurman RJ (ed). Blaustein's Pathology of the Female Genital Tract, 5th edn. Springer-Verlag: New York, 2002, pp 349-370.

12 Young RH, Clement PB. Endocervical adenocarcinoma and its variants: their morphology and differential diagnosis. Histopathology 2002;41:185-207.

13 Fujinaga Y, Shimada M, Okazawa K, et al. Simultaneous detection and typing of genital human papillomavirus DNA using the polymerase chain reaction. J Gen Virol 1991;72:1039-1044.

14 Kleter B, van Doorn LJ, ter Schegget J, et al. Novel short-fragment PCR assay for highly sensitive broadspectrum detection of anogenital human papillomaviruses. Am J Pathol 1998;153:1731-1739.

15 Munoz N. Human papillomavirus and cancer: the epidemiological evidence. J Clin Virol 2000;19:1-5.

16 Munoz N, Bosch FX, de Sanjose S, et al. International Agency for Research on Cancer Multicenter Cervical Cancer Study Group. Epidemiologic classification of human papillomavirus types associated with cervical cancer. N Engl J Med 2003;348:518-527.

17 An HJ, Cho NH, Lee SY, et al. Correlation of cervical carcinoma and precancerous lesions with human papillomavirus genotypes detected with the HPV DNA chip microarray method. Cancer 2003;97: 1672-1680.

18 Cho NH, An HJ, Jeong JK, et al. Genotyping of 22 human papillomavirus types by DNA chip in Korean women: comparison with cytologic diagnosis. Am J Obstet Gynecol 2003;188:56-62.

19 Reithdorf S, Riethodorf L, Milde-Langosch K, et al. Differences in HPV 16 and HPV 18 E6/E7 oncogene expression between in situ and invasive adenocarcinomas of the cervix uteri. Virchows Arch 2000;437: 491-500.

20 Pirog EC, Kleter B, Olgac S, et al. Prevalence of human paillomavirus DNA in different histological subtypes of cervical adenocarcinoma. Am J Pathol 2000;157: 1055-1062.

21 Zielinski GD, Snijders PJ, Rozendaal L, et al. The presence of high-risk HPV combined with specific p53 and p16 INK4a expression patterns points to high-risk HPV as the main causative agent for adenocarcinoma in situ and adenocarcinoma of the cervix. J Pathol 2003;201:535-543.

22 Kim CJ, Jeong JK, Park M, et al. HPV oligonucleotide microarray-based detection of HPV genotypes in cervical neoplastic lesions. Gynecol Oncol 2003;89: 210-217. 
23 Milde-Langosch K, Schreiber C, Becker G, et al. Human papillomavirus detection in cervical adenocarcinoma by polymerase chain reaction. Hum Pathol 1993;24:590-594.

24 Schwartz SM, Daling JR, Shera KA, et al. Human papillomavirus and prognosis of invasive cervical cancer: a population-based study. J Clin Oncol 2001; 19:1906-1915.

25 Im SS, Wilczynski SP, Burger RA, et al. Early stage cervical cancers containing human papillomavirus type 18 DNA have more nodal metastasis and deeper stromal invasion. Clin Cancer Res 2003;15:4145-4150.

26 Eifel PJ, Morris M, Oswald MJ, et al. Adenocarcinoma of the uterine cervix. Prognosis and patterns of failure in 367 cases Cancer 1990;65:2507-2514.

27 Hopkins MP, Morley GW. A comparison of adenocarcinoma and squamous cell carcinoma of the cervix. Obstet Gynecol 1991;77:912-917.
28 Fukushima M, Shimano S, Yamakawa Y, et al. The detection of human papillomavirus (HPV) in a case of minimal deviation adenocarcinoma of the uterine cervix (adenoma malignum) using in situ hybridization. Jpn J Clin Oncol 1990;20:407-412.

29 Ferguson AW, Svoboda-Newman SM, Frank TS. Analysis of human papillomavirus infection and molecular alterations in adenocarcinoma of the cervix. Mod Pathol 1998;11:11-18.

30 Toki T, Zhai YL, Park JS, et al. Infrequent occurrence of high-risk human papillomavirus and of p53 mutation in minimal deviation adenocarcinoma of the cervix. Int J Gynecol Pathol 1999;18:215-219.

31 Lee JY, Dong SM, Kim HS, et al. A distinct region of chromosome 19p13.3 associated with the sporadic form of adenoma malignum of the uterine cervix. Cancer Res 1998;58:1140-1143. 